\title{
Abundância, microhabitat e repartição ecológica de papa-formigas (Passeriformes, Thamnophilidae) na bacia hidrográfica do rio Tibagi, Paraná, Brasil
}

\author{
Edson V. Lopes; Graziele H. Volpato; Luciana B. Mendonça; Fernando de L. Fávaro \& Luiz dos Anjos
}

Departamento de Biologia Animal e Vegetal, Universidade Estadual de Londrina. Caixa Postal 6001, 86051-970 Londrina, Paraná, Brasil. Bolsista do CNPq. E-mail: papaformiga@yahoo.com.br

\begin{abstract}
Abundance, microhabitat and ecological partitioning of typical antbirds (Passeriformes, Thamnophilidae) in the Tibagi hydrographic basin, Paraná, Brazil. In this study, richness and abundance of Thamnophilidae were both evaluated and correlated with environmental parameters in four forest areas of the Tibagi river basin ( $\mathrm{Bl}, \mathrm{Ml}, \mathrm{Al}$ and $\mathrm{A} 2$ ), placed in an environmental gradient. In each site, the vegetation was characterized and, for each specie, was analyzed: 1) the microhabitat, 2) the spatial distribution and 3) the time spend in each foraging site (described here as foraging length). Bird species number was similar among areas, although, B1 inhabited higher abundance. The vegetation of this area, showed correlations relatively lower when compared to the other three, which showed higher values among themselves. Vine tangles in all strata, dense medium and higher strata and presence of clearings were representative in B1. Dense medium stratum showed representative to five species. On the other hand, vine tangles at the higher stratum and the absence of lower dense stratum were representative for only two species. The spatial distribution, the foraging length site and the microhabitats selection varied among the species. These were important factors in ecological partitioning of the species analyzed in this study.
\end{abstract}

KEY WORDS. Atlantic forest; foraging length; microhabitat; spatial distribution.

RESUMO. Neste estudo a riqueza e a abundância de Thamnophilidae foram avaliadas e correlacionadas com parâmetros ambientais em quatro áreas de floresta da bacia do rio Tibagi ( $\mathrm{B} 1, \mathrm{M1}, \mathrm{A} 1$ e $\mathrm{A} 2$ ) dispostas em um gradiente ambiental. Em cada área, foi caracterizada a vegetação e, para cada espécie, foram analisados: 1) o microhabitat, 2) a distribuição espacial e 3) o tempo investido em cada local de forrageio. $O$ número de espécies foi semelhante entre as áreas, contudo, em Bl foi registrada maior abundância. A vegetação desta área apresentou valor de correlação relativamente baixo quando comparada as outras três, que apresentaram valores maiores entre si. Emaranhados de cipó em todos os estratos, estrato médio e superior denso e ocorrência de clareiras foram variáveis representativas na área Bl. Estrato médio denso foi representativo para cinco espécies. Por outro lado, emaranhados de cipó no estrato superior e ausência de estrato inferior denso se destacaram apenas para duas espécies. A distribuição espacial, o tempo investido em cada local de forrageio e a seleção de microhabitats variaram entre as espécies. Esses foram fatores importantes na repartição ecológica das espécies analisadas neste estudo.

PALAVRAS-CHAVE. Distribuição espacial; duração do forrageio; floresta Atlântica; microhabitat.

Características dos habitats, críticas para a sobrevivência de certas espécies, são chamadas de microhabitats (Sтотz et al. 1996). Moitas de bambu, por exemplo, são consideradas o microhabitat de várias espécies de aves como Drymophila devillei (Menegaux \& Hellmayr, 1906) e Anabazenops dorsalis (Sclater \& Salvin, 1880) (Stotz et al. 1996, Kratter 1997). Outras espécies como Hylopezus fulviventris (Sclater, 1858) e Myrmeciza exsul (Sclater, 1859), dificilmente são encontradas longe de pequenas clareiras no interior da floresta (CODY 2000). Na região Neotropical, é relativamente grande a proporção de aves, principalmente as insetívoras, especializadas em microhabitats (Levey 1988, Wiens 1989, Schemske \& Brokaw 1981, Robinson 1990,
Rosenberg 1990, Stotz et al. 1996, Kratter 1997). Tal especialização pode influenciar na repartição ecológica das espécies permitindo a convivência de um maior número de espécies em uma dada área.

Composta por espécies essencialmente insetívoras, a família Thamnophilidae é um dos mais importantes componentes da avifauna Neotropical (SкUтсн 1996). Não é raro ser a família mais representada em inventários avifaunísticos de florestas neotropicais mais próximas da linha do Equador (BIERREGAARD \& Lovejoy 1989, BierregaArd 1990, Stouffer \& BierregaArd 1995, BierREgAARD \& STOUFFer 1997), região considerada como centro de evolução da família (KeAst 1990, Zimmer \& Isler 2003). 
Na bacia hidrográfica do rio Tibagi (BHT), principalmente em função de diferenças de altitude, estão presentes diferentes tipos de florestas (Torezan \& Silveira 2002). Anjos (2002) avaliou a abundância das espécies de aves florestais ao longo da BHT. Naquele estudo, o autor encontrou uma menor biomassa de Thamnophilidae na porção mais alta da BHT (em torno de $1.000 \mathrm{~m}$ de altitude) do que na porção mais baixa (em torno de $500 \mathrm{~m}$ de altitude).

No presente estudo, a abundância das espécies de Thamnophilidae é novamente analisada ao longo da BHT para comparar os padrões encontrados. O microhabitat destas é também analisado e relacionado com os padrões de abundância vindo esclarecer a repartição ecológica entre as espécies.

\section{MATERIAL E MÉTODOS}

\section{Áreas de estudo}

A BHT está localizada na região centro-leste do Estado do Paraná. O eixo maior da bacia corta o Estado no sentido sulnorte (Fig. 1). O desnível total do rio Tibagi, ao longo de seus quase $600 \mathrm{~km}$ de extensão, é de aproximadamente $750 \mathrm{~m}$, entre $1.060 \mathrm{~m}$ nas porções mais altas da bacia e $298 \mathrm{~m}$ na foz do rio. De acordo com a altitude do rio, três regiões podem ser reconhecidas na bacia: baixo, médio e alto Tibagi.

No baixo Tibagi, ocorre a floresta Estacional Semidecídua. Algumas espécies arbóreas representativas da floresta desta região são: Euterpe edulis Mart. (Arecaceae), Ficus glabra Vell. (Moraceae), Gallesia integrifolia (Spreng.) Harms (Phytolaccaceae) e Aspidosperma polyneuron Müll. Arg. (Apocynaceae). No alto Tibagi, ocorre a floresta Ombrófila Mista, além da vegetação gramíneo-lenhosa conhecida por Campos Gerais, em meio a qual estão manchas onde ocorre a formação natural de fragmentos com floresta Ombrófila Mista, chamados de capões. Representantes arbóreos típicos da floresta Ombrófila Mista desta região são: Podocarpus lanbertii Klotzsch ex Endl (Podocarpaceae), Ocotea porosa (Nees) Barroso (Lauraceae) e Araucaria angustifolia (Bertol.) O. Kuntze (Araucariaceae). No médio Tibagi, ocorre uma vegetação de transição entre a floresta Ombrófila Mista e a floresta Estacional Semidecídua. As espécies típicas de uma são gradualmente substituídas pelas da outra. Esta região é caracterizada como sendo uma zona de tensão entre aos dois tipos distintos de floresta que ocorrem nos extremos norte e sul da BHT.

Foram selecionadas, ao longo do eixo maior da BHT, quatro áreas (Fig. 1): o Parque Estadual Mata dos Godoy (23 $27^{\prime} \mathrm{S}$, $\left.51^{\circ} 14^{\prime} \mathrm{W}, 610 \mathrm{~m}\right)$, o Parque Ecológico da Klabin $\left(24^{\circ} 17^{\prime} \mathrm{S}, 50^{\circ}\right.$ $35^{\prime}$ W, 815 m), a Reserva Particular do Patrimônio Natural (RPPN) Tarumã ( $25^{\circ} 18^{\prime} \mathrm{S}, 49^{\circ} 49^{\prime} \mathrm{W}, 1.010 \mathrm{~m}$ ) e a Floresta Nacional (FLONA) de Irati $\left(25^{\circ} 24^{\prime} \mathrm{S}, 50^{\circ} 35^{\prime} \mathrm{W}, 920 \mathrm{~m}\right)$. Dentre as quatro áreas de estudo, a do Parque Estadual Mata dos Godoy é a que sofreu menor perturbação antrópica. As outras três áreas sofreram extração seletiva de árvores de grande porte mas estão há no mínimo 50 anos sem nenhum tipo de perturbação. Consideramos, portanto que, os quatro locais, atualmente apresentam alto grau de con-

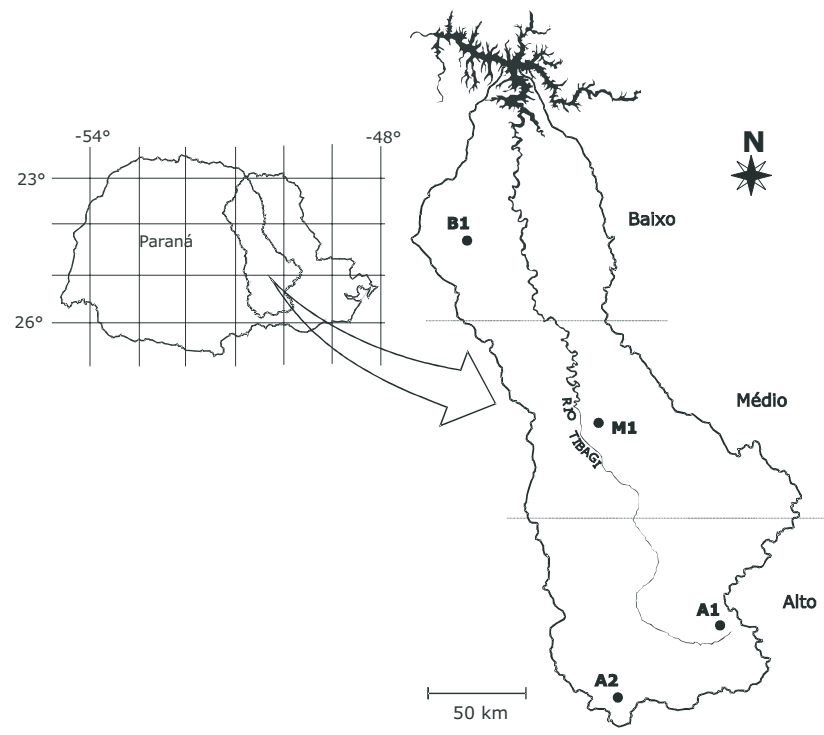

Figura 1. Localização das quatro áreas de estudo dentro da bacia hidrográfica do rio Tibagi (BHT): (B1) Parque Estadual Mata dos Godoy, (M1) Parque Ecológico da Klabin, (A1) Reserva Particular do Patrimônio Natural Tarumã e (A2) Floresta Nacional de Irati.

servação, sendo representativos da vegetação original.

O Parque Estadual Mata dos Godoy (B1), no baixo Tibagi, com 656 ha, apresenta floresta Estacional Semidecídua. Próximos ao Parque (até $1.000 \mathrm{~m}$ ), ligados ou não a ele por corredor florestal, existem vários remanescentes florestais em áreas particulares que formam um mosaico com cerca de 2.800 ha de floresta. A temperatura média anual é de $21^{\circ} \mathrm{C}$, com média máxima de $28^{\circ} \mathrm{C}$ e média mínima de $16^{\circ} \mathrm{C}$ e a média pluviométrica é de $1.600 \mathrm{~mm}$ (Mendonça \& Danni-Oliveira 2002).

O Parque Ecológico da Klabin (M1), no médio Tibagi, possui área de 11.116 ha. Deste total, 7.883 ha são ocupados por floresta nativa e o restante por reflorestamentos de $A$. angustifolia, Eucalyptus spp. (Myrtaceae) e Pinus spp. (Pinacea). Esta área apresenta uma floresta de transição entre o baixo e o alto Tibagi. A temperatura média anual é de $19,5^{\circ} \mathrm{C}$, com média máxima de $26^{\circ} \mathrm{C}$ e média mínima de $14,5^{\circ} \mathrm{C}$ e a média pluviométrica é de 1.700 mm (MENDonÇA \& DanNi-Oliveira 2002).

A Reserva Particular do Patrimônio Natural (RPPN) Tarumã (A1), com 840 ha, e a Floresta Nacional (FLONA) de Irati (A2), com 3.495 ha, dos quais 1.272 são remanescentes de floresta e o restante é ocupado por reflorestamentos de A. angustifolia, Eucalyptus spp. e Pinus spp., estão localizadas no alto Tibagi e apresentam floresta Ombrófila Mista, entretanto, a área A1 está localizada na região dos Campos Gerais, enquanto A2 é remanescente de uma floresta contínua. No alto Tibagi, a temperatura média anual é de $18^{\circ} \mathrm{C}$, com média máxima de $24^{\circ} \mathrm{C}$ e média mínima de $13^{\circ} \mathrm{C}$ e a média pluviométrica é de $1.550 \mathrm{~mm}$ (MeNDONÇA \& DANNI-OLIVEIRA 2002). 


\section{Riqueza e abundância}

Para as amostragens quantitativas foi utilizado o método de amostragem por pontos de escuta com distância ilimitada (Blondel et al. 1970, Vielliard \& Silva 1990). Com este método, é possível obter, além do registro da espécie, uma estimativa da sua abundância através do Índice Pontual de Abundância (IPA), que corresponde ao número total de contatos de uma espécie dividido pelo número total de pontos amostrados em uma dada área.

Em cada área, 12 pontos foram estabelecidos a cada 200 $\mathrm{m}$ ao longo de duas trilhas (seis pontos em cada trilha) com $1.000 \mathrm{~m}$ de comprimento cada. Estas trilhas foram determinadas paralelas entre si, a $300 \mathrm{~m}$ uma da outra e a pelo menos 100 $\mathrm{m}$ da borda da floresta. O tempo de permanência em cada ponto foi de 15 minutos, com tempo igual para deslocamento entre um ponto e outro. As amostragens foram iniciadas ao alvorecer, com o início das atividades das aves e prolongadas por duas horas e quarenta e cinco minutos, com a finalização do último ponto. A seqüência de amostragem dos pontos (P) foi sempre a mesma (P2, P4, P6, P5, P3, P1).

As amostragens foram sazonais (a cada 75-90 dias), ocorrendo em 2003 (primavera) e 2004 (verão, outono e inverno), completando um ciclo sazonal. Foram realizadas quatro sessões de amostragens em cada uma das quatro áreas. Cada sessão consistiu de dois dias de amostragens (um em cada trilha com seis pontos) realizados em dias consecutivos. Desta forma, foi obtido para cada área, um total de 48 pontos amostrados em oito dias de amostragens.

\section{Vegetação e microhabitat}

Para caracterizar a vegetação das áreas quanto a variáveis que pudessem ser relevantes para as espécies estudadas, foram analisadas 50 parcelas de $10 \times 10 \mathrm{~m}$ ao longo de cada trilha totalizando 100 parcelas em cada área. Em cada parcela, foi estimada a abundância de cinco tipos distintos de vegetação: 1) árvores, 2) bambu, 3) cipós, 4) xaxins e 5) mais de dois tipos sem predominância definida. Por estimativas, a vegetação mais abundante foi considerada predominante na parcela, e as análises foram feitas com base na proporção de parcelas em que determinado tipo de vegetação foi predominante em cada área.

Para a caracterização do microhabitat das espécies, foi adotada a metodologia empregada por MARRA \& REMSEN (1997) com algumas adaptações para as condições locais. No dia seguinte às amostragens quantitativas, a transecção era novamente percorrida e, após o contato com a espécie, o local exato em que o indivíduo vocalizava era determinado e considerado como o ponto central de uma parcela circular de $10 \mathrm{~m}$ de diâmetro. Nesta parcela eram coletadas informações sobre nove variáveis ambientais (Tab. I). Foram amostradas 25 parcelas para cada espécie em cada área estudada. Além de determinar o centro de cada parcela, sempre que possível o indivíduo era observado em atividade de forrageio. Durante esta observação foram registrados: 1) o tipo de substrato predominante (folhagem, emaranhados de cipó, bambu, arbusto, solo, xaxim e heterogêneo -três ou mais tipos) num raio de dois metro ao redor da ave, 2) a distribuição espacial (distância da ave com relação ao solo) e 3) o tempo de permanência da ave em cada local de forrageio (foi determinado que cada vez que a ave saísse de um raio de dois metros, seria considerada uma mudança de local de forrageio).

\section{Análise estatística}

O teste $G$, com o fator de correção de William $\left(G_{\text {adj }}\right)$, foi utilizado para comparar a riqueza de espécies das quatro áreas, a abundância de espécies (IPA X 100) que ocorreram em mais de uma área, a abundância total (abundância de todas as espécies somadas) e a biomassa total (IPA X massa corpórea da espécie segundo DunNing 1992). Diferenças na proporção de registros de substrato utilizado pelas espécies também foram avaliadas com o teste $G$, sem o fator de correção. A similaridade qualitativa e quantitativa entre as áreas foi avaliada com o Índice de Similaridade de Sørensen. Para comparação do número médio de contatos por amostragem foi utilizada análise de variância (ANOVA unifatorial/teste de Tukey). Para dados de distribuição espacial e tempo de forrageio das espécies foi utilizado o teste não-paramétrico (Kruskal-Wallis/teste de Dunn/MCP), pois não foram cumpridos os pressupostos de normalidade e homoscedasticidade para a utilização de teste paramétrico.

Correlações entre as áreas amostradas quanto à vegetação, foram testadas com o coeficiente de correlação por postos de Spearman $\left(r_{\mathrm{s}}\right)$. Análise dos Componentes Principais (ACP) foi empregada para avaliar a relação das variáveis ambientais estimadas de forma semiquantitativa. Para as ACPs foram retidos os eixos 1 e 2 e, em alguns casos, o 3 para interpretação dos dados e foram considerados o maior (ou maiores, no caso de valores muito próximos) auto-vetor(es) de cada eixo, como sendo o(s) mais representativo(s) na ordenação dos pontos.

Para algumas espécies, em função da baixa abundância, não foi possível a caracterização do microhabitat. Assim, foi realizada a caracterização do microhabitat de seis espécies em B1, cinco espécies em M1 e duas espécies em A1 e A2. Uma vez que a vegetação das quatro áreas diferiu entre si em algumas características, a análise do substrato registrado para cada espécie foi realizada para cada área separadamente. Por outro lado, a distribuição espacial média e o tempo médio de forrageio das espécies estudadas, que ocorreram em mais de uma área, não apresentaram diferença significativa entre as áreas, com exceção de Pyriglena leucoptera (Vieillot, 1818) (ANOVA, teste de Tukey, $\mathrm{p}<0,003$ ) e Herpsilochmus rufimarginatus (Temminck, 1822) (ANOVA, teste de Tukey, $\mathrm{p}<0,03$ ) que apresentaram diferença entre B1 e M1 em relação a distribuição espacial. Desta forma, os dados coletados em mais de uma área foram considerados em conjunto nas análises.

\section{RESULTADOS}

\section{Riqueza e abundância}

Foram registradas no total nove espécies de Thamnophilidae nos quatro locais de estudo na BHT: Hypoedaleus guttatus (Vieillot, 1816), Batara cinerea (Vieillot, 1819), Macken- 
Tabela I. Tratamento empregado às variáveis ambientais (1-9) utilizadas para caracterizar o microhabitat das espécies estudadas em cada área.

\begin{tabular}{cl}
\hline Variável & Tratamento \\
\hline 1 a 6 & $\begin{array}{l}\text { Presença em 0, 1, 2, } 3 \text { ou quatro quadrantes da parcela } \\
7 \text { a } 9\end{array}$ \\
$\begin{array}{l}\text { Estimativa com valores crescentes de } 0 \text { para ausência e } 4 \text { para máximo em 1, 2, } 3 \text { ou } 4 \text { quadrantes da parcela. Para análise } \\
\text { foi utilizado o valor médio dos quatro quadrantes de cada parcela }\end{array}$
\end{tabular}

1) Bambu, 2) Clareira, 3) Arbustos até $2 \mathrm{~m}$ de altura, 4) Emaranhados de cipós no estrato inferior (0-2 m), 5) Emaranhados de cipós no estrato médio (2-7 m), 6) Emaranhados de cipós no estrato superior (acima de $7 \mathrm{~m}), 7$ ) Densidade da vegetação no estrato inferior (0-2 $\mathrm{m})$, 8) Densidade da vegetação no estrato médio $(2-7 \mathrm{~m}), 9)$ Densidade da vegetação no estrato superior (acima de $7 \mathrm{~m}$ ).

ziaena severa (Lichtenstein, 1823), Thamnophilus caerulescens Vieillot, 1816, Dysithamnus mentalis (Temminck, 1823), $H$. rufimarginatus, Drymophila rubricollis (Bertoni, 1901), Drymophila malura (Temminck, 1825) e P. leucoptera. O número de espécies registrado em cada área foi semelhante $\left(G_{\text {adj }}=0,8 ; g l=3 ; p>0,01\right)$. Dysithamnus mentalis ocorreu nas quatro áreas com valores de abundância similares. Thamnophilus caerulescens foi a outra espécie que ocorreu nas quatro áreas, mas com abundância significativamente menor em B1. Duas outras espécies (H. guttatus e M. severa) ocorreram apenas em uma área (Tab. II).

A menor similaridade qualitativa $\left(C_{S}=0,4\right)$ ocorreu entre B1 e $A 2$ e a quantitativa $\left(C_{N}=0,67\right)$ entre $B 1$ e $A 1$. Os maiores valores de similaridade foram encontrados entre M1 e A1 $\left(C_{s}=0,92\right)$ e $A 1$ e $A 2\left(C_{N}=0,96\right)$.

Considerando a família em conjunto, o número médio de contatos por amostragem em B1 $(18,4 \pm 5,0)$ foi superior ao registrado em M1 $(11,8 \pm 2,7), \mathrm{A} 1(9,4 \pm 3,2)$ e $\mathrm{A} 2(10,1 \pm 4,8)$ (ANOVA, teste de Tukey, $\mathrm{p}<0,01$ ); M1, A1 e A2 não diferiram significativamente em relação a esta variável (ANOVA, teste de Tukey, p > 0,05). Da mesma forma, a abundância total e a biomassa total foram maiores em B1 (Tab. II) quando comparadas as outras três áreas que apresentaram valores semelhan- tes entre si em abundância total $\left(\mathrm{G}_{\mathrm{adj}}=2,2 ; \mathrm{gl}=2 ; \mathrm{p}>0,01\right)$ e biomassa total $\left(\mathrm{G}_{\mathrm{adj}}=0,2 ; \mathrm{gl}=2 ; \mathrm{p}>0,01\right)$.

\section{Estrutura da vegetação}

Quanto à predominância de variáveis da vegetação consideradas relevantes para as espécies estudadas, os maiores valores de correlação foram encontrados entre as áreas do médio e do alto Tibagi: M1-A1 $\left(r_{s}=0,60\right)$ e A1-A2 $\left(r_{s}=0,54\right)$. A área B1 apresentou baixos valores de correlação com M1 $\left(r_{s}=-0,15\right)$, com A1 $\left(r_{s}=0,39\right)$ e com A2 $(-0,21)$. Excetuando o componente arbóreo, comum a todas as áreas, cipós foram mais abundantes na área B1, enquanto moitas de bambu, puro ou associado com outros tipos de vegetação, predominaram em M1 ocorrendo também, em menor abundância em A1 e A2. A vegetação das áreas A1 e A2 mostrou-se mais semelhante entre si, com exceção da maior quantidade de xaxins encontrada em A2 (Tab. III).

\section{Microhabitat e repartição ecológica}

A variável ambiental que se mostrou representativa para o maior número de espécies foi estrato médio denso, que aparece com destaque para H. guttatus, M. severa, D. mentalis, D. rubricollis e P. leucoptera (Tab. IV). A variável arbustos, também, se destacou para cinco espécies: M. severa, D. mentalis, H. guttatus, T.

Tabela II. Índice Pontual de Abundância (IPA) das espécies, abundância total e biomassa total em cada área de estudo. A última coluna apresenta os valores do teste $\mathrm{G}$, com fator de correção $\left(\mathrm{G}_{\mathrm{add}}\right)$ e os graus de liberdade $(\mathrm{gl})$ de cada análise.

\begin{tabular}{|c|c|c|c|c|c|c|}
\hline \multirow{2}{*}{ Espécies } & \multicolumn{4}{|c|}{ Áreas } & \multicolumn{2}{|c|}{ Teste G } \\
\hline & B1 & M1 & $\mathrm{A} 1$ & $\mathrm{~A} 2$ & $\mathrm{G}_{\mathrm{adj}}$ & $\mathrm{gl}$ \\
\hline H. guttatus & 1,21 & - & - & - & - & - \\
\hline B. cinerea & - & 0,17 & 0,21 & 0,23 & $1,01 \mathrm{~ns}$ & 2 \\
\hline M. severa & 0,27 & - & - & - & - & - \\
\hline T. caerulescens & 0,08 & 0,35 & 0,40 & 0,50 & 35,80 * & 3 \\
\hline D. mentalis & 0,65 & 0,71 & 0,73 & 0,94 & $3,00 \mathrm{~ns}$ & 3 \\
\hline H. rufimarginatus & 0,06 & 0,04 & - & - & $0,04 \mathrm{~ns}$ & 1 \\
\hline D. rubricollis & - & 0,29 & 0,10 & 0,02 & 29,80 * & 2 \\
\hline D. malura & - & 0,02 & 0,04 & - & $0,65 \mathrm{~ns}$ & 1 \\
\hline P. leucoptera & 0,79 & 0,38 & 0,08 & - & 65,90 * & 2 \\
\hline Abundância total & 3,06 & 1,96 & 1,56 & 1,69 & 17,70 * & 3 \\
\hline Biomassa total & 97,5 & 58,5 & 53,6 & 57,1 & 30,30 * & 3 \\
\hline
\end{tabular}

$\left(^{*}\right) p<0,01,(n s)$ não significativo.

Revista Brasileira de Zoologia 23 (2): 395-403, junho 2006 
Tabela III. Vegetação predominante (porcentagem nas parcelas $\mathrm{n}$ = 100) ao longo das trilhas amostradas em cada área. (av) Árvore, (ab) árvore/bambu, (ac) árvore/cipó, (ax) árvore/xaxim, (bb) bambu, (va) mais de dois tipos de vegetação sem predominância definida.

\begin{tabular}{crrrrrr}
\hline \multirow{2}{*}{ Área } & \multicolumn{7}{c}{ Vegetação } \\
\cline { 2 - 7 } & av & ab & ac & ax & bb & va \\
\hline B1 & 18 & 0 & 78 & 0 & 0 & 4 \\
M1 & 26 & 39 & 7 & 1 & 18 & 9 \\
A1 & 56 & 18 & 5 & 4 & 3 & 14 \\
A2 & 45 & 20 & 0 & 22 & 4 & 9 \\
\hline
\end{tabular}

caerulescens e H. rufimarginatus, mas as três últimas foram relacionadas com ausência e apenas as duas primeiras com a presença de arbustos. Emaranhados de cipó no estrato superior se destacou apenas para T. caerulescens (presença) e para D. rubricollis (ausência). Ausência de estrato inferior denso destacou-se no microhabitat de $T$. caerulescens e $H$. rufimarginatus.

$\mathrm{Na}$ analise em conjunto das espécies de uma mesma área, o eixo 1 da ACP para as espécies estudadas em B1 explica 39\% da variância e é influenciado pela ocorrência de emaranhados de cipó no estrato inferior e no estrato superior e por estrato médio denso. O eixo 2 explica $16 \%$ e é influenciado pela ocorrência de clareiras, emaranhados de cipó no estrato médio e estrato superior denso (Fig. 2). O eixo 1 da ACP em M1 explica $38 \%$ da variância sendo influenciado pela presença de bambu e estrato superior pouco denso. O eixo 2 explica 14\% e é influenciado pela ausência de emaranhados de cipó no estrato inferior e pela presença de clareiras (Fig. 3).

Todas as espécies estudadas em B1 foram registradas com maior freqüência em emaranhados de cipó $(G=p<0,01)$. Contudo, $P$. leucoptera, D. mentalis e $M$. severa ocorreram também em outros tipos de substratos proporcionalmente mais do que $H$. rufimarginatus, $H$. guttatus e $T$. caerulescens. Em M1, apenas H. rufimarginatus foi encontrada preferencialmente em emaranhados de cipó, P. leucoptera em bambu e D. rubricollis exclusivamente em bambu. Dysithamnus mentalis e T. caerulescens ocorreram significativamente mais em folhagem, embora tenham sido mais generalistas em M1 do que em B1, explorando três tipos de substratos. Na área A2, estas duas espécies também mostraram-se generalistas, forrageando em vários tipos de substratos, enquanto em A1 foram encontrados apenas em folhagem e emaranhados de cipó (Tab. V).

A distribuição espacial foi diferente entre algumas espécies $(\mathrm{H}=225,9 ; \mathrm{p}<0,001)$. Herpsilochmus rufimarginatus foi mais registrado forrageando na copa, em locais em média mais altos que todas as outras espécies estudadas (Kruskal-Wallis, teste de Dunn/MCP, $\mathrm{p}<0,001$ ), com exceção de T. caerulescens, a quem foi marginalmente semelhante (Kruskal-Wallis, teste de Dunn/MCP, p > 0,07). Mackenziaena severa forrageou no estrato inferior, em média a mesma altura que $P$. leucoptera e $D$. rubricollis (Kruskal-Wallis, teste de Dunn/MCP, p > 0,05), em
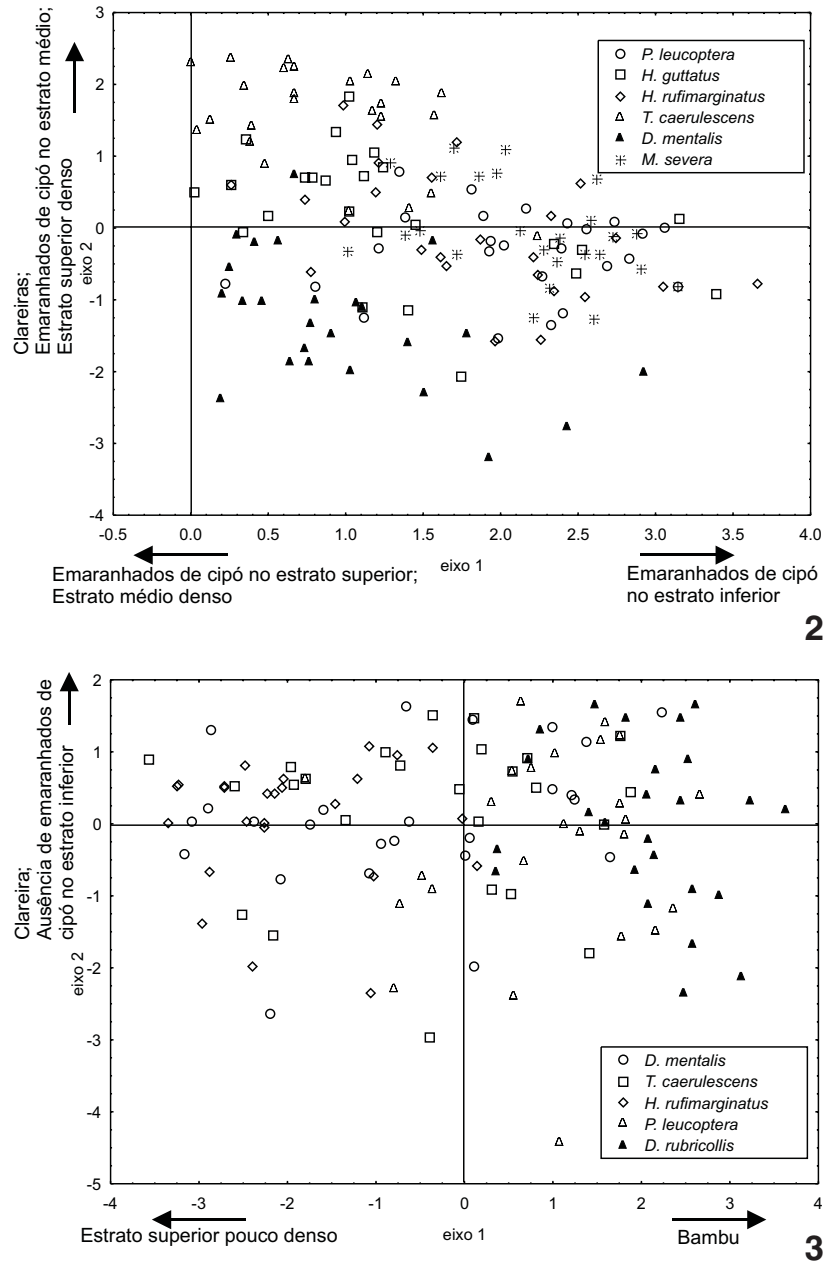

Figuras 2-3. Ordenação das parcelas de caracterização do microhabitat: (2) de seis espécies em B1, com base em oito variáveis semiquantitativas; (3) de cinco espécies em M1, com base em nove variáveis semiquantitativas. A variável bambu foi excluída da análise em B1 por não apresentar variação; valor zero em todas as amostras.

locais em média mais baixos que as outras espécies. Hypoedaleus guttatus forrageou no estrato médio, em média a mesma altura que D. mentalis e T. caerulescens (Kruskal-Wallis, teste de Dunn/ MCP, p > 0,05) (Tab. VI).

Em relação ao tempo de forrageio, também foram detectadas diferenças entre algumas espécies $(H=105,6 ; p<0,05)$. Herpsilochmus rufimarginatus permaneceu mais tempo em um mesmo ponto do que todas as outras espécies estudadas (KruskalWallis, teste de Dunn/MCP, $\mathrm{p}<0,04)$. Por outro lado, P. leucoptera foi a que permaneceu menos tempo em relação as outras espécies, (Kruskal-Wallis, teste de Dunn/MCP, p < 0,001). Hypoedaleus guttatus, D. mentalis, T. caerulescens e D. rubricollis, sem diferença entre si (Kruskal-Wallis; teste de Dunn/MCP, p > 0, 05), ficaram em situação intermediária. Mackenziaena severa não diferiu de

Revista Brasileira de Zoologia 23 (2): 395-403, junho 2006 
Tabela IV. Porcentagem de variância concentrada em cada eixo retido para ACP e variáveis de cada eixo que mais influenciaram na ordenação dos pontos (valor do auto-vetor).

\begin{tabular}{|c|c|c|c|}
\hline Espécie (n) & Eixo & $\begin{array}{c}\text { Variância } \\
\text { (\%) }\end{array}$ & Variável (auto-vetor) \\
\hline \multirow[t]{3}{*}{ H. guttatus (25) } & 1 & 39 & Estrato superior denso $(-0,47)$; ausência de emaranhados de cipó no estrato inferior $(0,47)$ \\
\hline & 2 & 17 & Ausência de arbustos $(-0,81)$ \\
\hline & 3 & 14 & Presença de emaranhados de cipó no estrato médio $(0,61)$; estrato médio denso $(0,48)$ \\
\hline \multirow[t]{3}{*}{ M. severa (25) } & 1 & 27 & Estrato médio denso $(-0,54)$ \\
\hline & 2 & 20 & Presença de emaranhados de cipó no estrato médio $(-0,57)$ \\
\hline & 3 & 16 & Presença de arbustos $(0,64) ;$ presença de clareiras $(0,54)$ \\
\hline \multirow[t]{3}{*}{ T. caerulescens $(100)$} & 1 & 33 & Presença de emaranhados de cipó no estrato superior $(-0,51)$ \\
\hline & 2 & 20 & Estrato inferior denso $(-0,52)$ \\
\hline & 3 & 12 & Ausência de arbustos $(-0,54)$; estrato superior denso $(0,79)$ \\
\hline \multirow[t]{3}{*}{ D. mentalis (100) } & 1 & 27 & Estrato médio denso $(-0,47)$ \\
\hline & 2 & 20 & Presença de emaranhados de cipó no estrato médio $(0,47)$ \\
\hline & 3 & 14 & Presença de bambu $(0,45) ;$ presença de arbustos $(-0,62)$ \\
\hline \multirow[t]{3}{*}{ H. rufimarginatus $(50)$} & 1 & 26 & Ausência de bambu $(0,43)$ \\
\hline & 2 & 22 & Ausência de emaranhados de cipós no estrato inferior $(0,50)$; estrato inferior pouco denso $(-0,43)$ \\
\hline & 3 & 14 & Ausência de arbustos $(0,51)$; estrato superior denso $(0,52)$ \\
\hline \multirow[t]{3}{*}{ D. rubricollis (25) } & 1 & 29 & Ausência de emaranhados de cipó no estrato superior $(-0,48)$ \\
\hline & 2 & 17 & Ausência de emaranhados de cipó no estrato médio $(-0,59)$; presença de clareiras $(0,50)$ \\
\hline & 3 & 14 & Estrato médio denso $(-0,64)$ \\
\hline \multirow[t]{3}{*}{ P. leucoptera (50) } & 1 & 38 & Presença de bambu $(-0,49)$ \\
\hline & 2 & 17 & Estrato superior pouco denso $(-0,69)$ \\
\hline & 3 & 12 & Estrato médio denso $(0,49)$; presença de clareiras $(-0,62)$ \\
\hline
\end{tabular}

Tabela V. Porcentagem de registro de substrato num raio de $2 \mathrm{~m}$ ao redor da ave. (ec) Emaranhados de cipó, (bb) bambu, (ab) arbustos, (fo) folhagem, (so) solo, (xx) xaxim, (ht) heterogêneo. Na última coluna estão os valores do teste $\mathrm{G}$ (G) e os graus de liberdade (gl) de cada análise.

\begin{tabular}{|c|c|c|c|c|c|c|c|c|c|c|}
\hline \multirow{2}{*}{ Área } & \multirow{2}{*}{ Espécie } & \multicolumn{7}{|c|}{ Substrato } & \multirow{2}{*}{ G } & \multirow{2}{*}{$\mathrm{gl}$} \\
\hline & & ec & $\mathrm{bb}$ & $a b$ & fo & so & $x x$ & ht & & \\
\hline B1 & H. guttatus & 85 & 0 & 0 & 15 & 0 & 0 & 0 & $54,0^{*}$ & 1 \\
\hline B1 & M. severa & 56 & 0 & 11 & 0 & 0 & 0 & 33 & $33,2^{*}$ & 2 \\
\hline B1 & T. caerulescens & 89 & 0 & 0 & 11 & 0 & 0 & 0 & $69,3^{*}$ & 1 \\
\hline B1 & D. mentalis & 66 & 0 & 0 & 34 & 0 & 0 & 0 & $10,4^{*}$ & 1 \\
\hline B1 & H. rufimarginatus & 92 & 0 & 0 & 8 & 0 & 0 & 0 & $82,9^{*}$ & 1 \\
\hline B1 & P. leucoptera & 51 & 0 & 31 & 0 & 4 & 0 & 14 & $55,2^{*}$ & 3 \\
\hline M1 & T. caerulescens & 29 & 21 & 0 & 50 & 0 & 0 & 0 & $13,3^{*}$ & 2 \\
\hline M1 & D. mentalis & 25 & 25 & 0 & 50 & 0 & 0 & 0 & $12,0^{*}$ & 2 \\
\hline M1 & H. rufimarginatus & 73 & 0 & 0 & 27 & 0 & 0 & 0 & $22,0^{*}$ & 1 \\
\hline M1 & D. rubricollis & 0 & 100 & 0 & 0 & 0 & 0 & 0 & - & - \\
\hline M1 & P. leucoptera & 0 & 62 & 33 & 0 & 5 & 0 & 0 & $57,5^{*}$ & 2 \\
\hline $\mathrm{A} 1$ & T. caerulescens & 53 & 0 & 0 & 47 & 0 & 0 & 0 & $0,3 \mathrm{~ns}$ & 1 \\
\hline $\mathrm{A} 1$ & D. mentalis & 14 & 0 & 0 & 86 & 0 & 0 & 0 & $57,6^{*}$ & 1 \\
\hline A2 & T. caerulescens & 4 & 0 & 0 & 88 & 0 & 8 & 0 & $131,3^{*}$ & 2 \\
\hline $\mathrm{A} 2$ & D. mentalis & 0 & 19 & 0 & 62 & 0 & 8 & 12 & $65,4^{*}$ & 3 \\
\hline
\end{tabular}

$\left.{ }^{*}\right) p<0,01$, (ns) não significativo. 
nenhuma espécie (Tab. VI). É possível que o teste aplicado não tenha sido capaz de detectar diferenças entre M. severa e as outras espécies, em função do baixo número de amostras, com elevado Desvio Padrão, obtidas para esta espécie.

Tabela VI. Valores médios \pm Desvio Padrão da distribuição espacial (metros acima do solo) e tempo de forrageio (segundos) das espécies estudadas. Letras iguais indicam semelhança entre as espécies (Kruskal-Wallis, teste de Dunn/MCP, $\alpha=0,05$ ).

\begin{tabular}{lcc}
\hline \multicolumn{1}{c}{ Espécies } & Distância do solo (n) & Tempo de forrageio (n) \\
\hline H. guttatus & $6,6 \pm 3,7 \mathrm{a}, \mathrm{c}(40)$ & $94,0 \pm 66,2 \mathrm{a}(32)$ \\
M. severa & $1,6 \pm 1,1 \mathrm{~b}(9)$ & $158,1 \pm 275,9 \mathrm{a}, \mathrm{b}, \mathrm{c}(8)$ \\
T. caerulescens & $8,0 \pm 2,8 \mathrm{a}(69)$ & $102,1 \pm 78,8 \mathrm{a}(55)$ \\
D. mentalis & $5,8 \pm 2,7 \mathrm{c}(122)$ & $112,6 \pm 79,1 \mathrm{a}(69)$ \\
H. rufimarginatus & $10,7 \pm 2,3 \mathrm{~d}(35)$ & $329,7 \pm 287,3 \mathrm{~b}(27)$ \\
D. rubricollis & $1,8 \pm 0,5 \mathrm{~b}(19)$ & $81,1 \pm 43,2 \mathrm{a}(19)$ \\
P. leucoptera & $1,0 \pm 0,9 \mathrm{~b}(72)$ & $30,1 \pm 41,3 \mathrm{c}(65)$ \\
\hline
\end{tabular}

\section{DISCUSSÃO}

Os padrões gerais de riqueza e abundância encontrados neste estudo são semelhantes aos registrados por ANJos (2002). Em ambos os estudos há maior abundância total e biomassa total da família na porção de menor altitude (norte) do que na porção de maior altitude (sul).

Hypoedaleus guttatus, M. severa, T. caerulescens, D. mentalis, e $P$. leucoptera mostraram exatamente o mesmo padrão nos dois estudos. Apenas duas espécies, Mackenziaena leachii (Such, 1825) e Biatas nigropectus (Lafresnaye, 1850), mencionadas por ANjos (2002) em M1 e A1, respectivamente, não foram registradas neste estudo. Ambas tiveram um único registro, demonstrando sua baixa abundância, o que explicaria a ausência delas no presente estudo. Oposto a isto, $D$. rubricollis foi registrada neste estudo e não por Anjos (2002), talvez pela ausência do microhabitat específico (moitas de bambu) na área amostrada naquele estudo.

O fato de as áreas M1, A1 e A2 serem mais semelhantes entre si do que a B1, quanto à composição das espécies e abundância de indivíduos, sugere que o tipo de floresta, que é mais semelhante entre estas três áreas com relação à B1, seja o principal fator gerador das diferenças encontradas no padrão de distribuição da família Thamnophilidae na BHT.

A maior abundância e biomassa da família em B1 pode ser, em parte, explicada pela maior quantidade de cipós que ocorre nesta área. Isto pode aumentar consideravelmente a densidade e, conseqüentemente, a complexidade da vegetação (PuTz 1984). Não considerando a interferência de inúmeros fatores, que podem variar localmente, como a produtividade primária e a presença de competidores de outros grupos, a correlação entre a complexidade da vegetação e a abundância de aves, geralmente é positiva, especialmente para aves de pequeno porte, que se abrigam e capturam artrópodes em meio a vegetação densa, como a maioria dos Thamnophilidae, (PEARson 1975, WIENS, 1989).

O microhabitat formado pelos emaranhados de cipós é preferencialmente explorado em B1 por todas as espécies estudadas naquela área. A preferência por forragear em emaranhados de cipó é observada em muitos membros da família Thamnophilidae (Zimmer \& IsLer 2003), além disto, a floresta Estacional Semidecídua que ocorre na região onde B1 está situada é mais semelhante, em termos estruturais, às florestas Ombrófilas Densas que ocorrem na costa Atlântica e na Amazônia, as quais são dois importantes centros de distribuição da família Thamnophilidae (KeAsT 1990, Zimmer \& Isler 2003), do que à floresta Ombrófila Mista que se assemelha mais às florestas temperadas do sul da América do Sul, onde a família é menos representativa em número de espécies (ZIMMER \& IsLer 2003).

Outra explicação para a variação, já abordada por ANJos (2002), é a diferença de temperatura e sazonalidade entre os extremos da BHT. Tais diferenças são devidas aos gradientes altitudinal (cerca de $750 \mathrm{~m}$ ) e latitudinal (quase quatro graus) que ocorrem ao longo da BHT, no sentido sul-norte, e podem afetar a distribuição dos artrópodes que são a base da alimentação dos Thamnophilidae.

Em alguns estudos sobre a distribuição de aves em gradientes altitudinais esta família é a que mais diminui em riqueza e abundância em direção ao topo do gradiente altitudinal (Terborgh 1971, 1977, Young et al. 1998, Blake \& Loiselle 2000), seguindo o padrão apresentado por vários grupos de artrópodes (JANZEN 1973a, b). Em estudo realizado por MARINONI \& DUTRA (1991), foi analisada parte da entomofauna em oito localidades do Estado do Paraná, três delas (Jundiaí do Sul, Telêmaco Borba e Ponta Grossa) representantes do mesmo tipo de floresta que ocorre em B1, M1 e A1/A2, respectivamente. Naquele estudo, a variável meteorológica que apresentou maior correlação com a densidade média mensal de insetos capturados foi a temperatura. Apesar da densidade média de insetos capturados diminuir de forma semelhante nestes três locais nos meses mais frios do ano, o aumento da densidade nos meses mais quentes na área de floresta Estacional Semidecídua foi superior ao registrado nas áreas de floresta Ombrófila Mista. Além disso, representantes de ordens importantes na dieta alimentar de aves insetívoras, como Orthoptera, Lepidoptera e Coleoptera apresentaram maior densidade na floresta Estacional Semidecídua em relação ao registrado na floresta Ombrófila Mista (Marinoni \& Dutra 1991).

Dentre os fatores analisados, os que mais diferenciam as espécies de estrato inferior (D. rubricollis, P. leucoptera e M. severa) parecem ser a seleção de diferentes microhabitats e/ou o tempo médio de forrageio. A especialização de D. rubricollis em bambu está bem documentada (Willis 1988, Leme 2001a, b), neste estudo esta espécie foi registrada exclusivamente em bambu, sendo alto o seu grau de especialização. Em M1, P. leucoptera 
forrageou em moitas de bambu, como descrito por Willis \& ONIKI (1982), contudo, a maior abundância da espécie foi registrada em B1 onde ela forrageou em emaranhados de cipó e vegetação arbustiva, que ocorrem em clareiras no interior da floresta, sugerindo ser este o microhabitat preferencial da espécie, como citado por Aleixo (1999). Mackenziaena severa explorou em B1 substrato semelhante a $P$. leucoptera, porém com tempo de forrageio maior e, aparentemente, preferência por clareiras maiores.

Herpsilochmus rufimarginatus, em B1, mostrou preferência pelo mesmo tipo de substrato que as espécies de estrato médio (H. guttatus, T. caerulescens e D. mentalis), mas evitou a competição direta ao forragear em locais mais altos e também com tempo médio de forrageio muito inferior que o das outras espécies estudadas. Espécies que forrageiam mais rápido provavelmente capturam presas mais conspícuas, enquanto as que se detêm por mais tempo em cada local de forrageio podem encontrar presas mais ocultas na vegetação (RoBinson \& Holmes 1982).

Semelhanças na distribuição espacial e velocidade de forrageio de $H$. guttatus, $T$. caerulescens e D. mentalis sugerem para estas espécies uma maior sobreposição de nicho. Entretanto, $T$. caerulescens e D. mentalis forragearam em mais tipos de substratos. Além disso, tais espécies apresentaram maior amplitude vertical em sua área de forrageio quando comparadas às espécies de estrato inferior. A grande amplitude da altura de forrageio de $H$. rufimarginatus se deveu ao fato desta espécie ocasionalmente ter forrageado na copa de árvores emergentes.

Variações no grau de especialização, somado à ocorrência de determinados microhabitats ao longo de um gradiente ambiental, ocasionam diferenças na composição e na abundância de espécies da família Thamnophilidae na BHT. De uma forma geral, as espécies mais generalistas, estiveram presentes em mais áreas, do que aquelas que forragearam em um microhabitat específico.

O maior grau de especialização foi demonstrado por $D$. rubricollis, que alcançou maior abundância na área onde foi evidenciada a maior representatividade de bambu, e esteve ausente na área onde não ocorreu este microhabitat. No outro extremo, está D. mentalis, que explorou substratos tão distintos quanto emaranhados de cipós, folhagem e moitas de bambu e manteve populações com tamanhos semelhantes ao longo de todo o gradiente ambiental analisado.

\section{AGRADECIMENTOS}

Este estudo contou com apoio da Universidade Estadual de Londrina (UEL) e do CNPq, através do Programa de Mestrado em Ciências Biológicas da UEL (processo 350054/95-9) e do projeto "Monitoramento da Biodiversidade em Bacias Hidrográficas da Mata Atlântica" (Programa Mata Atlântica: processos 690146/01-9, 350054/95-9 e 350054/95-9). Luiz dos Anjos agradece pela bolsa de produtividade em pesquisa concedida pelo CNPq (processo 350054/95-9). Agradecemos, pelas facilidades proporcionadas, às seguintes instituições: Instituto
Ambiental do Paraná, Instituto Brasileiro do Meio Ambiente e dos Recursos Naturais Renováveis e Indústria Klabin de Papel e Celulose. A José Ragusa Netto e dois consultores anônimos pelas sugestões sobre o manuscrito.

\section{REFERÊNCIAS BIBLIOGRÁFICAS}

Aleixo, A. 1999. Effects of selective logging on a bird community in the Brazilian Atlantic Forest. The Condor, Lawrence, 101: 537-548.

ANJos, L. Dos. 2002. Forest bird communities in the Tibagi river hydrographic basin, southern Brazil. Ecotropica, Bonn, 8: 67-79.

BierRegaARD JR., R.O. 1990. Avian communities in the understory of the Amazonian forest fragments, p. 333-343. In: A. KEAST (Ed.) Biogeography and ecology of forest bird communities. The Hague, SPB Publishing, 410p.

BierREgaARD JR., R.O. \& T.E. Lovejoy. 1989. Effects of forest fragmentation on Amazonian understory bird communities. Acta Amazônica, Manaus, 19: 215-241.

BierRegaARd JR., R.O. \& P.C. Stouffer. 1997. Understory birds and dynamic habitat mosaics in Amazonian rainforest, p. 138154. In: F.W. Laurance \& R.O. BierregaARd JR. (Eds) Tropical forest remnants: ecology, management, and conservation of fragmented communities. Chicago, The University of Chicago press, $\mathrm{XV}+616 \mathrm{p}$.

Blake, J.G. \& B.A. Loiselle. 2000. Diversity of birds along an elevational gradient in the Cordilheira Central, Costa Rica. The Auk, Missolua, 117: 663-686.

Blondel, J.; C. Ferry \& B. Frochot. 1970. La méthode des indices ponctuels d'abondance (I.P.A.) ou des relevés d'avifaune par stations d'écoute. Alauda, Paris, 38: 55-71.

Cody, M.L. 2000. Antbird guilds in the lowland Caribbean rainforest of southeast Nicarágua. The Condor, Lawrence, 102: 784-794.

DunNing JR., J.B. 1992. CRC handbook of avian body masses. Boca Raton, CRC Press, 384p.

JANZEN, D.H. 1973a. Sweep samples of tropical foliage insects: description of study sites, with data on species abundances and size distributions. Ecology, Durham, 54: 659-686.

JANZEN, D.H. 1973b. Sweep samples of tropical foliage insects: effects of seasons, vegetation types, elevation, time of day, and insularity. Ecology Durham, 54: 689-709.

KeAst, A. 1990. Distribution and origins of forest birds, p. 4560. In: A. KEAST (Ed.). Biogeography and ecology of forest bird communities. The Hague, SPB Publishing, 410p.

Kratter, A.W. 1997. Bamboo specialization by Amazonian birds. Biotropica, Washington, 29: 100-110.

Leme, A. 2001a. Foraging patterns and resource use in four sympatric species of antwrens. Journal Field of Ornithology, Lawrence, 72: 221-227.

LEME, A. 2001b. Foraging substrate selection by Ochre-rumped Antbird Drymophila ochropyga. Ararajuba, Londrina, 9: 7-11. Levey, D.J. 1988. Tropical wet forest treefall gaps and 
distributions of understory birds and plants. Ecology, Tempe, 69: 1076-1089.

Marinoni R.C. \& R.R.C. Dutra. 1991. Levantamento da fauna Entomológica no Estado do Paraná. I. Introdução. Situações climática e florística de oito pontos de coleta. Dados faunísticos de agosto de 1986 a julho de 1987. Revista Brasileira de Zoologia, Curitiba, 8: 31-73.

Marra, P.P. \& J.V. Remsen JR. 1997. Insight into the maintenance of high species diversity in the neotropics: habitat selection and foraging behavior in understory birds of tropical and temperate forests. Ornithological Monographs, Fayetteville, 48: 445-483.

Mendonça, F. De A. \& M.I. Danni-Oliveira. 2002. Dinâmica atmosférica e tipos climáticos predominantes da bacia do rio Tibagi, p. 63-68. In: M.E. Medri; E. Bianchini; O.A. Shibata \& J.A. Pimenta (Eds). A bacia do rio Tibagi. Londrina, Edição dos editores, $595 \mathrm{p}$.

Pearson, D.L. 1975. The relation of foliage complexity to ecological diversity of three Amazonian bird communities. The Condor, Lawrence, 77: 453-466.

Putz, F.E. 1984. The natural history of lianas on Barro Colorado Island, Panama. Ecology, Tempe, 65: 1713-1724.

Robinson, S.K. 1990. Lowland tropical forest bird communities of a site in Western Amazonia, p. 229-258. In: A. KeAst (Ed.). Biogeography and ecology of forest bird communities. The Hague, SPB Publishing, 410p.

Robinson, S.K. \& R.T. Holmes. 1982. Foraging behavior of forest birds: the relationships among search tactics, diet and habitat structure. Ecology, Durham, 63: 1913-1918.

Rosenberg, G.H. 1990. Habitat specialization and foraging behavior by birds of Amazonian river islands in northeastern Peru. The Condor, Lawrence, 92: 427-443.

SCHEMSKE, D.W. \& N. BROKAW. 1981. Treefalls and the distribution of understory birds in a tropical forest. Ecology, Durham, 62: 938-945.

SKUTCH, A.F. 1996. Antbirds and ovenbirds. Austin, University of Texas Press, XVIII+268p.

Recebido em 02.VI.2005; aceito em 25.IV.2006
Stotz, D.F.; J.W. FitzPatrick; T.A. Parker III \& D.K. Moskovits. 1996. Neotropical birds: ecology and conservation. Chicago, University of Chicago Press, 481p.

Stouffer, P.C. \& R.O. BierregaArd JR. 1995. Use of Amazonian forest fragments by understory insectivorous birds. Ecology, Tempe, 76: 2429-2445.

Terborgh, J. 1971. Distribution on environmental gradients: theory and a preliminary interpretation of distributional patterns in the avifauna of the cordillera Vilcabamba, Peru. Ecology, Durham, 52: 23-40.

Terborgh, J. 1977. Bird species diversity on an Andean elevational gradient. Ecology, Durham, 58: 1007-1019.

Torezan, J.M.D. \& M. Silveira. 2002. Fatores ambientais, diversidade e similaridade em florestas da bacia do rio Tibagi, p. 125134. In: M.E. Medri; E. Bianchini; O.A. Shibata \& J.A. Pimenta (Eds). A bacia do rio Tibagi. Londrina, Edição dos editores, 595p.

Vielliard, J.M.E. \& W.R. Silva. 1990. Nova metodologia de levantamento quantitativo e primeiros resultados no interior do Estado de São Paulo, p. 117-151. In: S.M. Azevedo Jr. (Ed.). Anais do IV encontro Nacional de Anilhadores de Aves. Recife, Universidade Federal Rural de Pernambuco, 151p.

Wiens, J.A. 1989. The ecology of bird communities. Cambridge, Cambridge University Press, vol. 1, XIII+539p.

Willis, E.O. 1988. Drymophila rubricollis (Bertoni 1901) is a valid specie (Aves, Formicariidae). Revista Brasileira de Biologia, Rio de Janeiro, 48: 431-438.

Willis, E.O. \& Y. ONiki. 1982. Behavior of Fringe-backed Fireeyes (Pyriglena atra, Formicariidae): a test case for taxonomy versus conservation. Revista Brasileira de Biologia, Rio de Janeiro, 42: 213-223.

Young, B.E.; D. De Rosier \& G.V.N. Powell. 1998. Diversity and conservation of understory birds in the Tilarán Mountains, Costa Rica. The Auk, Missoula, 115: 998-1016.

ZIMMER, K.J. \& M.L. IsLER. 2003. Family Thamnophilidae (Typical antbirds), p. 448-681. In: J. Del Hoyo; A. Elliot \& D.A. Christie (Eds). Handbook of the birds of the wolrd. Barcelona, Lynx Edicons, vol. 8, 845p. 